\title{
General Medical Considerations for the Wilderness Adventurer: Medical Conditions That May Worsen With or Present Challenges to Coping With Wilderness Exposure
}

\author{
Tracy A. Cushing, MD, MPH; William O. Roberts, MD, MS; Peter Hackett; William W. Dexter, MD; \\ Jeff S. Brent, MD; Craig C. Young, MD; Jessie R. Fudge, MD; Seth C. Hawkins, MD; \\ Thomas G. DeLoughery, MD; Benjamin J. Thomas, MD; Geoffrey C. Tabin, MD; \\ Leah E. Jacoby, MD; Chad A. Asplund, MD, MPH \\ From the Department of Emergency Medicine, University of Colorado School of Medicine, Aurora, Colorado (Drs Cushing and Hackett); the \\ Department of Family Medicine and Community Health, University of Minnesota, St. Paul, Minnesota (Dr Roberts); the Institute for Altitude \\ Medicine, Telluride, Colorado (Dr Hackett); the Department of Family Medicine, Tufts University School of Medicine, Boston, Massachusetts \\ (Dr Dexter); the Department of Sports Medicine, The Vancouver Clinic, Vancouver, Washington (Dr Brent); the Department of Orthopedics/ \\ Community \& Family Medicine, Medical College of Wisconsin, Milwaukee, Wisconsin (Dr Young); the Department of Family Medicine, Group \\ Health Cooperative, Everett, Washington (Dr Fudge); the Department of Emergency Medicine, University of North Carolina School of Medicine, \\ Chapel Hill, North Carolina (Dr Hawkins); the Departments of Medicine, Pediatrics and Pathology, Oregon Health and Science University, \\ Portland, Oregon (Dr DeLoughery); the Department of Ophthalmology, John A. Moran Eye Center, University of Utah, Salt Lake City, Utah \\ (Drs Thomas and Tabin); the Department of Emergency Medicine, Denver Health Medical Center, Denver, Colorado (Dr Jacoby); and the \\ Department of Family Medicine, Georgia Regents University, Augusta, Georgia (Dr Asplund).
}

\begin{abstract}
Participation in wilderness and adventure sports is on the rise, and as such, practitioners will see more athletes seeking clearance to participate in these events. The purpose of this article is to describe specific medical conditions that may worsen or present challenges to the athlete in a wilderness environment.
\end{abstract}

Key words: preparticipation evaluation, wilderness athlete, chronic medical conditions

\section{Introduction}

Participation in wilderness and adventure sports is on the rise; thus, practitioners will see more athletes seeking clearance to participate in such events. The purpose of this article is to describe specific medical conditions that may worsen or present challenges to the athlete in a wilderness environment. Recommendations are organized by organ system to help providers ensure a thorough evaluation for wilderness activities.

The authors report no conflicts of interest.

This article appears in a "Care of the Wilderness and Adventure Athlete" special issue, jointly published by Clinical Journal of Sport Medicine and Wilderness \& Environmental Medicine.

Corresponding author: Tracy A. Cushing, MD, MPH, Mail Stop B 12 Leprino Building, 12401 E 17th Ave Room 763, Aurora, CO 80045 (e-mail: tracycushing@gmail.com).

\section{Methods}

The following databases were searched: MEDLINE and Cochrane Database of Systematic Reviews. Articles were limited to those printed in English between 1980 and May 2014. Key terms included preparticipation physical evaluation and wilderness athlete. These terms were cross-matched with the term "medical condition." This process yielded 27 published articles. The articles and references as well as several textbooks were reviewed for use in this article.

\section{Cardiovascular Conditions}

Evaluation of wilderness adventure participants should address potential cardiac conditions that may worsen with exertion, altitude, heat, or cold. Most athletes can exercise and participate in wilderness activities without cardiac risk. Altitude, heat, or cold exposure can aggravate ischemic 
conditions without exertion in patients with underlying disease. Differentiating risk level and making participation recommendations is an important component of medical clearance for patients with cardiac disease.

\section{WILDERNESS RISK FACTORS FOR HEART DISEASE}

Specific environmental exposures can worsen cardiovascular disease. Cold stress increases mean arterial pressure, total peripheral resistance, cardiac workload, and myocardial oxygen requirements during both rest and exercise, ${ }^{1,2}$ which can increase risk for angina and other cardiac events. ${ }^{2}$ Cold water swimming has been shown to change or mask angina symptoms, also placing patients at risk. ${ }^{1,3}$ Hot conditions vasodilate peripheral vessels and cause additional cardiovascular demands to aid in body cooling. Hot and dry conditions can lead to body water losses and further stress the diseased cardiovascular system. The risk of sudden cardiac death in hikers at altitude increases with age in an exponential fashion starting in the fourth decade. ${ }^{4}$ Although altitude will increase the workload on the heart due to lower partial pressure of oxygen, altitude does not increase the risk of acute coronary syndrome above that at sea level for the same workload in stable coronary artery disease (CAD). ${ }^{5}$

\section{PREPARTICIPATION HISTORY AND PHYSICAL EXAMINATION}

In addition to a good history to screen for heart disease and the symptoms of CAD and congenital heart disease, attention should be given to patient preparedness and expected environmental conditions. Knowing a patient's anticipated exertion level, duration of exposure, wilderness experience, and cardiac history allows for targeted education to decrease risk. Screening questions, such as those recommended by the American Heart Association, ${ }^{6}$ should be directed at individual and family history. The examination should include a general assessment of age, sex, ethnicity, blood pressure, heart rate, the cardiovascular system, peripheral pulses, and the physical manifestations of Marfan syndrome to evaluate for potential vascular pathology. For patients with newly detected or longstanding hypertension, good control should be established before embarking on these strenuous activities.

\section{CLEARANCE: RISK FACTOR MODIFICATION/ RECOMMENDATIONS}

Positive responses to the screening questions or abnormalities on examination may suggest increased risk of cardiac events during physical activity, and each positive response should be pursued to determine the need for additional diagnostic studies like an electrocardiogram, exercise stress test, echocardiogram, cardiac computed tomography or magnetic resonance imaging, or electrophysiological studies.

For patients with hypertension, blood pressure should be controlled with medications that pose the least risk in the anticipated environment. Angiotensin-converting enzyme inhibitors, calcium channel blockers, and central $\alpha$-agonists seem to cause the least problems during exercise and diuretics work well if potassium is maintained in the normal range. ${ }^{7}$

To ameliorate cardiac risk, the best treatment is prevention. The preparticipation examination (PPE) provides an opportunity to educate patients on their specific risk factors and strategies to reduce risk during activity in harsh or difficult environments, away from the usual medical response systems common to metropolitan areas. There are several resources available to assist the practitioner in making clearance decisions such as the 36th Bethesda Guidelines for sports participation and the PPE monograph (fourth edition).

Specific recommendations should be discussed with patients who have been identified as having a higher risk of cardiac disease: optimizing medical management of their cardiovascular or other medical conditions; entering a conditioning program well in advance of departure to build endurance for the activity; avoiding or quitting cigarette smoking and tobacco use; using caution when exercising in extremes of temperature (hot or cold); being familiar with their angina symptoms; and being aware that low-oxygen environments may provoke undetected ischemia or worsen usually stable congestive heart failure.

\section{Pulmonary Conditions}

Lung diseases are common in those who present for pretrip evaluations. Asthma, exercise-induced bronchospasm (EIB), and chronic obstructive pulmonary disease (COPD) are the most common conditions seen. The pretrip evaluation must include a history of previous events, an assessment of current lung function and exercise tolerance, consideration of comorbidities, a plan to ensure optimal health before and during the activity, a discussion of selftreatment options should problems develop, and a plan for emergencies. Important considerations include the level of exercise expected, exposure to air pollution, dust and allergens, access to medical care, and logistics of evacuation. High-altitude activities pose a special problem for patients with lung disease and are discussed in more detail elsewhere in this issue.

Both asthma and EIB should be in good control before clearance for wilderness activity. ${ }^{8}$ For asthmatic divers, 
what to advise and whether to do pretrip spirometry is controversial; clinical practice varies. Some authors state that the use of a rescue short-acting beta-agonist (SABA) in the previous 48 hours is considered a contraindication to diving. ${ }^{9}$ See Doan and Luks ${ }^{10}$ for a recent review of this unsettled issue, including the recommendations of multiple organizations. For these bronchospastic conditions, it is important to attempt to identify risk factors for exacerbation, such as the cold and dry air of high altitude, dust, and allergens and plan accordingly. The use of a warming face mask can be helpful for the former and a balaclava or similar covering for the latter. EIB is more common at high altitude and liberal use of SABA for this should be encouraged.

The management and decision-making process for COPD for wilderness activities is similar to asthma: optimal condition before activity, monitoring during the activity, and responding to problems as necessary. For patients with COPD, oxygen has a major role. Should they require home oxygen at baseline, portable oxygen concentrators are available that can be powered by regular electricity if available or by batteries with limited duration, with car/vehicle adapters, or solar power. For patients not on home oxygen but who are traveling to altitude and will likely need oxygen, physicians should consider an oxygen prescription and an inexpensive pulse oximeter for their patients. It is important that patients with COPD have resolved any recent exacerbation and be well functioning on a stable medical regimen before travel. Persons with mild COPD can tolerate modest altitude $(<2750 \mathrm{~m})$, but moderate-tosevere patients with COPD most often cannot, except with supplemental oxygen. Patients must be accustomed to exercise comparable with their planned activity and understand recognition and management of increasing wheezing and dyspnea. Practitioners may consider oral steroids with instruction for their use, as well as SABA or other bronchodilators. Please also refer to the COPD section within the Special Populations paper.

\section{Central Nervous System Disorders}

Common neurological conditions such as epilepsy and headache disorders are not necessary contraindications to wilderness participation. However, safe participation requires good judgment on the part of the patient and the physician. When conducting the PPE, 2 major points should be considered: knowledge and stability of the patient's specific condition and the environment into which they will travel.

Seizure disorders present a common dilemma for the practitioner. Seizures can be well controlled with medications, allowing the person with epilepsy to participate in many activities. Aerobic activity has been shown to decrease seizure frequency. ${ }^{11}$ Seizures have many different triggers, some of which may be exacerbated by outdoor activities such as high altitude and/or heat. ${ }^{7,8}$ The proposed mechanisms for this include hypoxia, fatigue, stress, and poor sleep. Many studies show reduced sleep quality at high altitude. ${ }^{12,13}$ Underwater activities such as SCUBA diving, skydiving, and free climbing (and other sports at height) are all absolutely contraindicated in someone with a poorly controlled seizure disorder.

Headache disorders are common and may be exacerbated in the wilderness setting or mimic-specific wilderness-related pathology. High-altitude exposure may cause acute mountain sickness (AMS) where the cardinal sign is headache. AMS can progress into high-altitude cerebral edema if unrecognized and be life threatening. It can often be difficult to differentiate a primary headache from AMS. ${ }^{14}$ Because of this, patients with chronic headaches should be aware of the risk of a potentially disabling headache at high altitude and the difficulty of differentiating between the headache of AMS and other types of headache.

Multiple sclerosis (MS) may become symptomatic or worsen in extreme environments. Patients with MS exhibit heat intolerance, which may cause a worsening of symptoms. Caution must be advised when participating in a hot environment or an event that elevates body temperature beyond what a patient with MS is familiar with in-training; precooling before exercise may benefit the MS participant, allowing them to exercise longer. ${ }^{15}$ Although there are no adverse effects on MS from high altitude, ${ }^{16}$ high-pressure environments such as SCUBA diving can present challenges to the patient with MS as many of the hallmarks of decompression sickness overlap MS symptomatology. ${ }^{17}$ Therefore, this risk should be addressed with the patient with MS before any diving excursion.

Parkinson disease (PD) causes autonomic dysfunction that may lead to difficulties in thermoregulation, thereby increasing the risk of hypothermia in cold conditions. Because of this, if a trip is attempted in a cold environment or at high altitude, patients with PD should have the guidance of healthy individuals. ${ }^{16}$ Finally, medication timing is very important; patients should not allow "wearing off' that can lead to functional immobility in the outdoor environment, creating a dangerous situation. Therefore, it is important to ensure ready access to medications or prompt delivery if supplies are exhausted, which can be critical in these situations.

\section{Gastrointestinal Disorders}

The evaluation process of the gastrointestinal (GI) system should focus on acute processes and the stability 
of chronic illnesses. Particular attention should be given to signs of organomegaly and acute GI disease. In patients with acute GI symptoms, particularly from infectious or inflammatory causes, consideration should be given to some type of restriction in diet, activity, or trip departure date depending on the type of wilderness activity planned. Thus, the PPE for the GI tract should focus on (1) history of GI problems and (2) the presence of acute or chronic GI infection or disease.

Acute infectious disease is the most common cause of diarrhea in the backcountry, ${ }^{18}$ often due to suboptimal hygiene in many wilderness settings. Because of the increased need for fluid ingestion with diarrhea, participation should be avoided until resolution of acute GI symptoms if dehydration is a concern. Participants should consider carrying antimotility medications but should be cautioned to avoid their use with dysenteric diarrhea (fever or blood in stool) as this may worsen infection; however, patients with nondysenteric diarrhea may use antimotility agents liberally to prevent fluid and electrolyte loss. ${ }^{19}$ The importance of hand hygiene and sanitary food preparation should also be emphasized preparticipation; so, patients can avoid becoming ill while on their trip.

Constipation is another common problem in the wilderness traveler, which can be further exacerbated by diets that tend to be low in fresh vegetables and fruits, and high in low fiber, refined foods because of weight and storage considerations. Medications to prevent constipation should be used with caution because excessive GI fluid loss increases risk of dehydration. Therefore, aggressive hydration, bulk agents, and stool softeners are usually preferred over osmotic agents.

If PPE physical examination reveals hepatomegaly or splenomegaly, there is risk of injury from trauma and full participation should be avoided until resolution. Splenic rupture related to infectious mononucleosis may also occur with relatively low forces (eg, with Valsalva of bowel movement) and tends to occur within the first 3 weeks of the disease. Patients with acute splenomegaly should delay wilderness expeditions until after this point. $^{20}$

Chronic GI disease can present a greater challenge because simply delaying the trip is not an option. Individuals with chronic liver disease may have multiple underlying problems, including lower stamina, increased risk of bleeding, and suboptimal nutritional status. Individuals with chronic malabsorption syndromes may also have suboptimal nutritional status. ${ }^{21}$ Individuals with ulcerative colitis and Crohn's disease should continue on their usual medication regimes. In addition, a course of prednisone should be carried for use in cases of an acute flare.

\section{Musculoskeletal Disorders}

Chronic musculoskeletal concerns are common in the adventure athlete and should be addressed before participation. The PPE should include a detailed history and evaluation of an injured or previously treated area before activity to allow for risk assessment, guidance, and activity modification as needed. ${ }^{19}$ Providers should assess the short- and long-term risks and benefits related to participation in the setting of chronic musculoskeletal concerns, in particular to determine if the athlete can participate safely with minimal risk of injury. ${ }^{21}$

Physical activity is recommended for the treatment and management of many chronic conditions, including osteoarthritis (OA). ${ }^{22}$ The risk of clinical or radiographic progression of $\mathrm{OA}$ is increased with regular participation in recreational sports; however, the risk is less than in the overweight population or in joints exposed to trauma. ${ }^{23}$ The risk of OA is increased in obesity, joint trauma (especially ACL disruption in the knee), and a family history of OA. There is little evidence that OA progresses with activity beyond the natural progression in those with known associated risk factors. Athletes should be counseled on their risks but can continue their activity in the setting of radiographic or clinical OA as long as the activity is not painful or that pain is well managed with conservative therapies, such as ice, elevation, nonsteroidal anti-inflammatories, or therapeutic massage. ${ }^{23}$ The use of trekking poles for walking has been shown to decrease force through the lower extremity and may be recommended for athletes with knee arthritis or other knee injuries. ${ }^{24,25}$

There are very few randomized studies that identify risk of sport participation in athletes with total joint replacement. Clearance decisions must include an assessment of the patient's overall health, the joint replaced, and the preoperative involvement and skill in the activity being discussed. The risk of increased wear, premature prosthesis failure, periprosthetic fracture, and need for revision surgery should also be considered. ${ }^{26}$ Limited guidance exists for sport participation after joint replacement (Table). ${ }^{28}$ Researchers who studied biomechanical forces through a total knee replacement (TKR) during different activities agreed with the consensus on avoiding jogging or running postreplacement. ${ }^{29}$ Given high tibiofemoral loads through the knee with downhill walking/hiking, athletes with a TKR should use caution, trekking poles, and limit their pack weight to decrease the risk of early wear of the loadbearing surface. ${ }^{24,25,29}$ Mountaineering should be practiced with caution, especially lead climbing, to decrease the risk of high-impact falls. ${ }^{30}$ Athletes in suitable physical condition, with prior experience, good rehabilitation from their injury or surgery, with normal 


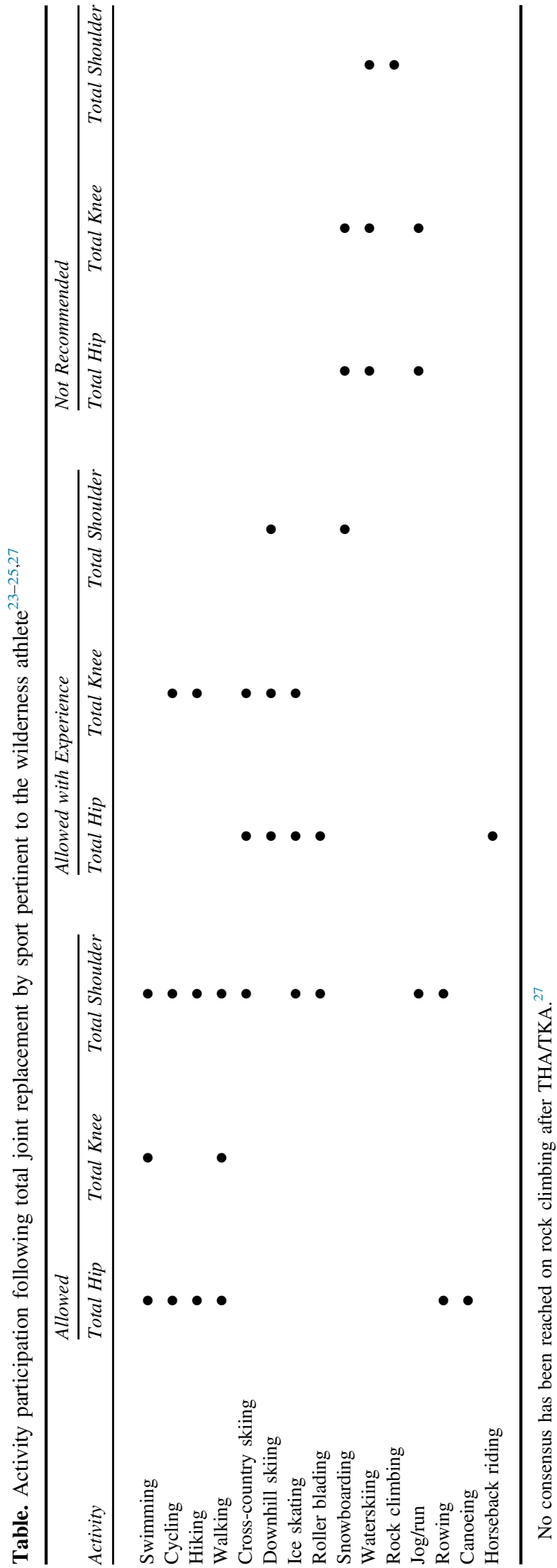

proprioception, balance, and strength should be able to participate in most activities.

\section{Hematologic Disorders}

Blood-related disorders, both innate and acquired, are a frequent issue in wilderness medical care and screening. One study shows up to a $5 \%$ prevalence of Factor $\mathrm{V}$ Leiden thrombophilia in the general population. ${ }^{31}$ As of 2007, 42 million Americans were taking anticoagulants routinely, ${ }^{32}$ and $3 \%$ of all patients presenting to trauma centers in the preceding 5 years were anticoagulated. ${ }^{33}$ Despite this, hematological conditions are rarely covered in traditional wilderness medical courses and may pose a challenge even to experienced medical screening personnel. In addition, the few hematological recommendations commonly used in screening tools are often outdated given the recent introduction of novel hematological drugs. ${ }^{34}$

\section{IATROGENIC COAGULOPATHY}

One of the more common hematological conditions encountered by medical screening personnel is iatrogenic coagulopathy, where individuals' blood is intentionally made less capable of clotting, either through the use of traditional agents such as low-molecular weight heparin or warfarin or the use of more recently introduced novel oral anticoagulants (NOACs, such as apixaban, rivaroxaban, and dabigatran). Anticoagulants are used in an increasingly younger and more athletic population, and there is now direct marketing of NOACs to an older population promoting the specific idea that wilderness activities are now safer with these new drugs. ${ }^{35}$ However, there is little medical literature guiding medical screeners and risk managers in the appropriate screening for iatrogenically coagulopathic participants in wilderness activities. Existing protocols such as those maintained by major experiential education schools and wilderness medicine schools have been criticized as outdated regarding management of warfarin-induced coagulopathies, ${ }^{34}$ and generally they do not address NOACs at all.

One review of this has been published, including preliminary recommendations for medical screening of intentionally anticoagulated patients. ${ }^{34}$ These recommendations suggested that some wilderness activities could be safe for anticoagulated patients and suggest that some feature of NOACs might actually be more beneficial for wilderness applications versus warfarin. NOACs do not require monitoring of blood levels and are generally not affected by diet or other drugs. The appropriateness of preliminary wildernessscreening recommendations has been heavily debated in the medical literature; this topic remains highly contentious, putting the onus on medical screeners and trip 
leaders to navigate the various perspectives. ${ }^{36,37}$ However, some features of warfarin and NOAC use have uncontested implications for wilderness activities. For example, patients on warfarin may see changes in their international normalized ratio (INR) based on trip activities even if these levels are traditionally stable before a trip. Patients with febrile illness can show increased INR, which can be further exacerbated by primary (poor intake) or secondary (to vomiting or diarrhea) dehydration. ${ }^{34}$ Abrupt increases in activity level can decrease $\mathrm{INR}^{34}$ altitude can decrease $\mathrm{INR},{ }^{38}$ and atypical diets in travelers can expose patients to foods that unexpectedly alter INR, sometimes drastically. Patients on NOACs have less need for monitoring blood levels and controlling diet, but there is also less experience about safety in cases of spontaneous or traumatic bleeding. Specific data becoming available may help steer medical screeners to identify particular risk factors for bleeding and mortality in patients based on their indication for anticoagulation and the type of anticoagulant used. In nearly all studies, NOACs appear to have a reduced overall risk of major bleeding when compared with warfarin. $^{32,39}$ Exceptions exist based on specific NOAC and indication for use (eg, dabigatran shows reduced bleeding incidence relative to warfarin when used for atrial fibrillation, but a similar study evaluating dabigatran in heart valve patients was halted preliminarily due to apparent increased risk of bleeding). ${ }^{40}$ Although bleeding rates may be reduced in NOACs versus warfarin, mortality rates appear similar. ${ }^{41}$ In addition, for da-bigatran, age older than 70 years and renal insufficiency were risk factors for major bleeding ${ }^{41}$ (both of these can be screened before wilderness activities although there is debate as to the possibility and significance of unexpected renal insufficiency during a wilderness or adventure trip). ${ }^{36,37}$ GI bleeding appears more common than intracranial hemorrhage for dabigatran ${ }^{42,43}$ although the significance of this for travel/wilderness recreation is also a subject of debate. ${ }^{36,37}$

Participants on other agents disrupting the clotting process, such as clopidogrel or aspirin, may have risks equivalent to participants on warfarin or NOACs, and this seems to be underappreciated in the medical screening and wilderness medicine community. Although many major studies show reduced overall risk of bleeding in NOACs, ${ }^{32,39}$ the National Emergency XRay Utilization Study-II group found the same rate of intracerebral hemorrhage (one in 8) in patients suspected to be coagulopathic from any source, including nonwarfarin drugs. ${ }^{44}$ The CREST network study demonstrated that rates of intracerebral hemorrhage are significantly higher in clopidogrel users than warfarin users. ${ }^{45}$ This suggests that clopidogrel use might be as important as warfarin use in medical screening and that head trauma in clopidogrel users might need as much or more urgency in the wilderness setting than patients taking warfarin. ${ }^{34}$

\section{THROMBOPHILIA CARRIERS}

Many patients will be found to be carriers of thrombophilia traits such as Factor V Leiden. ${ }^{31}$ Although these patients are at higher risk of thrombosis during their lifetime, the day-to-day risk is low unless there is another provoking factor present such as trauma or estrogens. These patients should not be precluded from participations in wilderness activities. The only medical implications of carrying a hypercoagulable trait is that if patients have trauma, especially lower limb, they are at higher risk of thrombosis and require antithrombotic prophylaxis. Also if they need to fly more than 6 hours, knee high compression stockings are at effect at preventing thrombosis. ${ }^{46}$ Aspirin has been shown in a randomized clinical trial not to be effective in preventing thrombosis in carriers of Factor V Leiden and should not be prescribed for this purpose.

\section{BLEEDING DISORDERS}

Bleeding disorders are common with 1:10 000 men having hemophilia and up to 1:1000 people having von Wil-lebrand disease. Modern therapy with factor replacement allows people with hemophilia to participate in any type of activity. Planning is essential before any adventure to be sure that the participant had adequate factor to cover any bleeds and in sufficient amount to allow for delay in evacuation. ${ }^{47}$ Most patients with von Willebrand disease can use nasal desmopressin for bleeding. It can be stored at room temperature allowing it to be performed on most trips.

\section{SICKLE CELL TRAIT}

Up to $10 \%$ of African Americans carry sickle cell trait, but it can be found in all ethnic groups, including whites. Trait patients are asymptomatic but may be more prone to develop heat stroke/rhabdomyolysis with extreme exertion in hot environments. Given the prevalence of sickle cell trait, it is more sensible to prevent dehydration and overheating in all participants than screening certain ethnic groups. ${ }^{48}$ A unique presentation of trait is splenic infarction at high altitude such as ski resorts. For unknown reasons, this occurs almost exclusively in whites. ${ }^{49}$ Patients with known trait should be advised to maintain hydration and to limit exertion in hot areas until acclimated.

\section{IRON DEFICIENCY}

Iron deficiency is very common in women (up to 33\%) and can negatively affect performance. Studies now 
show that repletion of iron stores, even in nonanemic patients, can improve performance and well-being. ${ }^{50}$ Target goal is ferritin greater than $50 \mathrm{ng} / \mathrm{dL}$. For highaltitude adventures, a higher goal of greater than $75 \mathrm{ng} /$ $\mathrm{dL}$ may be desirable to allow for high-altitude red-cell expansion.

\section{Opthalmologic Disorders}

Ocular considerations for the PPE are visual acuity, the presence of chronic disease affecting the eyes, and need for protective eyewear. Essentially, the pertinent questions are is the patient's vision sufficient for the activity in question? If so, is the presence of chronic disease affecting the patient's vision to a debilitating degree? Finally, does the trip environment increase risk for visual complications?

Vision should be formally assessed with a Snellen chart (or equivalent). If vision is sufficiently reduced, affected patients must either wear spectacles, contacts, or consider refractive surgery. Each option has unique advantages and disadvantages for the wilderness athlete.

Spectacles provide the advantages of protection (especially when made of shatterproof polycarbonate) and carry no infection risk. However, they are prone to breaking, may not be stable during robust activity, and suffer from fogging and dirt accumulation.

Contact lenses (CLs) come in several varieties such as rigid gas permeable (RGP) and soft, and because they are worn on the eye surface, they often provide clearer vision with greater versatility than spectacles. However, they are both prone to drying and subsequent foreign body sensation (FBS), require solution and cleaning, and carry risk of ulcerative keratitis. ${ }^{33}$ RGPs are more likely to cause FBS and dislodge from the ocular surface, ${ }^{51}$ whereas soft CLs (especially extended wear and overnight users) carry greater risk of infection. ${ }^{27,52}$ Therefore, CL users who head into the wilderness should be appropriately cautioned about lens hygiene and infection risk.

Finally, there are several concerns for those adventurers who have had a history of refractive surgery. Radial keratotomy (RK) uses partial thickness corneal incisions and can weaken the structural integrity of the cornea increasing risk of open-globe injury with trauma. ${ }^{51}$ Refractive techniques pose risk to people at altitude: RK causes a hyperopic shift that can severely reduce near vision, ${ }^{53-55}$ and LASIK can cause reduced vision from a myopic shift. ${ }^{56-58}$ PRK has not shown vision changes in studies at altitude although it may lead to increased corneal swelling compared with nonsurgical eyes. ${ }^{55}$

If the patient's visual acuity cannot be corrected by one of the above techniques, the possibility of organic ocular disease should be investigated with a comprehensive eye examination before clearance for wilderness sports.

Extreme conditions such as hypoxic environments represent risks to the vascular structures of the eye, ${ }^{59-62}$ and caution should be exercised when evaluating any patient with existing retinopathy or a history of vascular disease. Sudden vision loss in one or both eyes frequently represents vascular injury-either to the retina, optic nerve, or visual cortex - and should always prompt emergent evaluation, which should be discussed with the athlete. Another more chronic disease of the optic nerve, glaucoma, rarely worsens acutely with environmental stressors; however, topical and oral medicines used to treat glaucoma (such as $\beta$-blockers or carbonic anhydrase inhibitors) may affect the body's ability to acclimatize to high altitude, ${ }^{51,63}$ and a thorough medication history is always warranted in these cases.

Along with the considerations listed above, monocular patients (decreased visual acuity in 1 eye) should be counseled about eye safety precautions and the use of polycarbonate protective lenses. With appropriate awareness and precautions, one can help assure good vision for any patient headed outdoors.

\section{Psychiatric Disorders}

Psychiatric illnesses, whether diagnosed or undiagnosed, are common. As such, there are a growing number of participants in wilderness activities who are currently undergoing or have previously undergone some type of psychiatric treatment, and there are special considerations in regards to preparticipation evaluation for participants with psychiatric illness in wilderness activities.

A positive wilderness experience can be life changing for youths, adolescents, and adults suffering from a range of psychiatric diseases, and many studies have shown the benefits of outdoor education on social functioning. ${ }^{64-68}$ However, there are potential aspects of the wilderness experience that should be addressed before participation, in an attempt to avoid a negative experience both for the individual and the group as a whole.

Four key elements that should be included in the PPE screening of all participants with known psychiatric conditions are (1) current medications, (2) substance use and abuse history, (3) coping skills and response to stress, and (4) previous psychiatric hospitalizations.

Providers should ask about medications: their indications, duration of treatment, and the patient' s compliance with treatment. As many psychotropic medications take weeks to reach their therapeutic level, those with 
new or recent diagnoses should not participate until on a stable medication regimen. Many medications will yield harmful side effects if stopped suddenly; therefore, the participant should have an adequate supply of medications before the trip. Youths or adolescents should also have instructors/guides who know how to administer medications or supervise their consumption appropriately. Many of these medications have side effects (eg, drowsiness) that may have potential effects on the patient's activity. In addition, many psychiatric medications put users at risk for developing heat stroke, heat exhaustion, or hyperthermia through neuroleptic malignant syndrome, serotonin syndrome, or polypharmacy in a hot environment.

Substance use or abuse should be screened for and addressed. Withdrawal from alcohol or benzodiazepines can be potentially life threatening, especially in austere environments. Chronic opiate and narcotic users are at an increased risk of withdrawal symptoms as well. Nicotine use should be addressed in the PPE, and patients involved in a trip where they are unable to smoke should be warned that they may have severe withdrawal symptoms including anxiety, restlessness, and agitation that can be detrimental to a wilderness experience and should be offered alternatives such as patches or nicotine gum.

Another consideration is the ability to cope with potential stressors, which may be increased in an extreme environment. The wilderness experience can cause a heightened stress level as people are out of their comfort zone, out of their daily routine, participating in activities that are physically demanding, and living in close quarters with others who may be strangers to them. If participants have had previous problems handling stressful situations or crises or do not have adequate coping methods in place, they may have increased difficulty adapting to a wilderness setting. Therefore, a frank discussion with the participant about the advantages and disadvantages of traveling into a wilderness environment should be part of the evaluation.

Finally, participants should be questioned about previous psychiatric hospitalizations or suicide attempts. An increased frequency of hospitalizations or recent discharge from an inpatient unit should raise some concern for the provider that this patient will need a more thorough evaluation before being permitted to participate in a wilderness activity. Participants with underlying psychiatric or substance abuse problems are those that potentially stand to benefit the most from a wilderness experience, especially in the youth and adolescent population; thus, a thorough PPE should address these issues before their wilderness trip to ensure that they will have a positive experience.

\section{Summary}

As the participation in wilderness events becomes more popular, the likelihood of participation by those with existing medical conditions will also increase. It is important for safety and for the enjoyment of the participant that medical conditions, especially those that could worsen in remote or extreme environments, be addressed and optimized before travel. Finally, the preparticipation consult allows an excellent time for education on medication and equipment use, warning signs of worsening disease and general safety tips to ensure safe participation in most wilderness pursuits.

\section{References}

1. Castellani JW, Young AJ, Ducharme MB, et al. ACSM position stand: prevention of cold injuries during exercise. Med Sci Sports Exerc. 2006;38:2012-2029.

2. Epstein S, Stampfer M, Beiser D, Goldstein R. Effects of a reduction in environmental temperature on the circulatory response to exercise in man: implications conerning angina pectoris. N Engl J Med. 1969;280:7-11.

3. Madger S, Linnarsson D, Gullstrand L. The effects of swimming on patients with ischemic heart disease. Сirculation. 1981;63:979-986.

4. Burtscher M, Philadelphy M, Likar R. Sudden cardiac death during mountain hiking and downhill skiing. $N$ Engl J Med. 1993;329:1738-1739.

5. Schmid JP, Noveanu M, Gaillet R, et al. Safety and exercise tolerance of acute high altitude exposure (3454 m) among patients with coronary artery disease. Heart. 2006;92:921-925.

6. American Academy of Family Physicians, American Academy of Pediatrics, American College of Sports Medicine, American Medical Society for Sports Medicine, American Orthopaedic Society for Sports Medicine, American Osteopathic Academy of Sports Medicine. Preparticipation Physical Evaluation. 4th ed. Bernhardt DT, Roberts WO, eds. Elk Grove, Illinois: American Academy of Pediatrics; 2010.

7. Chick TW, Halperin AK, Gacek EM. Effect of antihypertensive medications on exercise performance: a review. Med Sci Sports Exerc. 1988;20:447-454.

8. Durand FI, Kippelen P, Ceugniet F, et al. Undiagnosed exercise-induced bronchospasm in ski-mountaineers. Int J Sports Med. 2005;26:233-237.

9. Lynch JH, Bove AA. Diving medicine: a review of current evidence. J Am Board Fam Med. 2009;22:399-407.

10. Doan D, Luks AM. Wilderness and adventure travel with underlying asthma. Wilderness Environ Med. 2014;25: 231-240.

11. Howard GM, Radloff M, Sevier TL. Epilepsy and sports participation. Curr Sports Med Rep. 2004;3:15-19.

12. Roach GD, Schmidt WF, Aughey RJ, et al. The sleep of elite athletes at sea level and high altitude: a comparison of 
sea-level natives and high-altitude natives (ISA3600). Br J SportsMed. 2013;47(suppl 1):i114-i120.

13. Szymczak RK, Sitek EJ, Slawek JW, et al. Subjective sleep quality alterations at high altitude. Wilderness Environ Med. 2009;20:305-310.

14. Karle FJ III, Auerbach PS. Migraine headache confounding the diagnosis of acute mountain sickness. Wilderness Environ Med. 2014;25:60-68.

15. White AT, Wilson TE, Davis SL, et al. Effect of precooling on physical performance in multiple sclerosis. Mult Scler. 2000;6:176-180.

16. Baumgartner RW, Siegel AM, Hackett PH. Going high with preexisting neurological conditions. High Alt Med Biol. 2007;8:108-116.

17. Jan MH, Jankosky CJ. Multiple sclerosis presenting as neurological decompression sickness in a U.S. navy diver. Aviat Space Environ Med. 2003;74:184-186.

18. Gentile DA, Morris JA, Schimelpfenig T, et al. Wilderness injuries and illnesses. Ann Emerg Med. 1992;21:853-861.

19. Adachi JA, Backer HD, DuPont HL. Infectious Diarrhea from Wilderness and Foreign Travel in Wilderness Medicine. 4th ed. Auerbach PS, ed. St. Louis MO: Mosby; 2001:1237-1270.

20. Putukian M, O'Connor FG, Stricker PR, et al. Mononucleaosis and athletic participation: an evidence-based subject review. Clin J Sport Med. 2008;18:309-315.

21. American Academy of Family Physicians, American Academy of Pediatrics, American College of Sports Medicine, American Society for Sports Medicine, American Orthopedic Society for Sports Medicine, American Osteopathic Academy of Sports Medicine. Systems-Based Examination: Gastrointestinal/Genitourinary in PPE Preparticipation Physical Evaluation. 4th ed. Bernhardt DT, Roberts WO, eds. Elk Grove Village, IL: American Academy of Pediatrics; 2010:97-101.

22. American College of Sports Medicine, Position Stand, Exercise and physical activity for older adults. Med Sci Sports Exerc. 2009; 7:1510-1530.

23. Vignon E, Valat JP, Rossignol M, et al. Osteoarthritis of the knee and hip and activity: a systematic international review and synthesis (OASIS). Joint Bone Spine. 2006;73:442-455.

24. Willson J, Torry MR, Decker MJ, et al. Effects of walking poles on lower extremity gait mechanics. Med Sci Sports Exerc. 2000;33:142-147.

25. Schwameder H, Roithner R, Muller E, et al. Knee joint forces during downhill walking with hiking poles. J Sports Sci. 1999;17:269-278.

26. Vogel LA, Giuseppe B, Carotenuto B, et al. Physical activity after total joint arthroplasty. Sports Health. 2011;3:441-450.

27. Liesegang TJ. Contact lens-related microbial keratitis: part I: epidemiology. Cornea. 1997;16:125-131.

28. Klein GR, Levine BR, Hozack WJ, et al. Return to athletic activity after total hip arthroplasty. J Arthroplasty. 2007;22:171-175.

29. Kuster MS, Splainger E, Blanksby BA, Gachter A. Endurance sports after total knee replacement: a biomechanical investigation. Med Sci Sports Exerc. 2000;32:721-724.

30. Peters P. Mountain sports and total hip arthroplasty: a case report and review ofmountaineering with total hip arthroplasty. Wilderness Environ Med. 2003;14:106-111.

31. Herrmann FH, Koesling M, Schrŏder W, et al. Prevalence of factor V Leiden mutation in various populations. Genet Epidemiol. 1997;14:403-411.

32. Raja AS, Geyer B. Emergency department management of patients on novel oral anticoagulant agents. Emerg Med Pract. 2013;15:2.

33. Dossett LA, Riesel JN, Griffin MR, et al. Prevalence and implications of preinjury warfarin use: an analysis of National Trauma Databank. Arch Surg. 2011;146:565-570.

34. Hawkins SC, Caudell MJ, DeLoughery TG, et al. Participation of iatro-genically coagulopathic patients in wilderness activities. Wilderness Environ Med. 2013;24:257-266.

35. Janssen Pharmaceuticals, Inc. Jim. Available at: http:// www.ispot.tv/ad/7qPs/xarelto-jim. Accessed May 15, 2014.

36. Darracq MA, Young M. Novel anticoagulants should NOT be recommended for high-risk activity. Wilderness Environ Med. 2014;25:359-360.

37. Hawkins SC, Caudell MJ, Deloughery TG, et al. Activity recommendations for anticoagulated patients may differ, but should be based on accurate data interpretation. Wilderness Environ Med. 2014;25:360-361.

38. Van Patot MC, Hill AE, Dingmann C, et al. Risk of impaired coagulation in warfarin patients ascending to altitude (>2400 m). High Alt Med Biol. 2006;7:39-46.

39. Granger CB, Alexander JH, McMurray JJ, et al. Apixaban versus warfarin in patients with atrial fibrillation. $N$ Engl $J$ Med. 2011;365:981-992.

40. Eikelboom JW, Connolly SJ, Brueckmann M, et al. Dabigatran versus warfarin in patiens with mechanical heart valves. N Engl J Med. 2013;369:1206-1214.

41. Connolly SJ, Ezekowitz MD, Yusuf S, et al. Dabigatran versus warfarin in patients with atrial fibrillation. $N$ Engl J Med. 2009;361:1139-1151.

42. Berger R, Salhanick SD, Chase M, et al. Hemorrhagic complications in emergency department patients who are receiving dabigatran compared with warfarin. Ann Emerg Med. 2013;61:475-479.

43. Harper P, Young L, Merriman E. Bleeding risk with dabigatran in the frail elderly. $N$ Engl J Med. 2012;366: L864L-L8866.

44. Medzon R, Bracken M, Rathlev NK, et al. Clinically suspected coagulopathy in blunt head trauma. J Emerg Med. 2010;39:399-405.

45. Nishijima DK, Offerman SR, Ballard DW, et al. Immediate and delayed traumatic intracranial hemorrhage in patients with head trauma and preinjury warfarin or clopidogrel use. Ann Emerg Med. 2012;59:460-468.

46. Kahn SR, Lim W, Dunn AS, et al. American College of Chest Physicians. Prevention of VTE in nonsurgical patients: Antithrombotic Therapy and Prevention of Thrombosis, 9th ed: American College of Chest Physicians 
Evidence-Based Clinical Practice Guidelines. Chest. 2012;141(2 suppl 1):e195S-e226S.

47. Grissom CK, Luks AM, DeLoughery TG. Chronic diseases and wilderness activities. Chapter 34. In: Auerbach PS, ed. Wilderness Medicine 6th ed. Atlanta, Georgia: Elsevier; 2012:645-663.

48. American Society of Hematology. Sickle cell trait. Available at: http://www.hematology.org/Patients/Anemia/ Sickle-Cell-Trait.aspx. Accessed May 21, 2014.

49. Franklin QJ, Compeggie M. Splenic syndrome in sickle cell trait: four case presentations and a review of the literature. Mil Med. 1999;164:230-233.

50. Pasricha SR, Low M, Thompson J, et al. Iron supplementation benefits physical performance in women of reproductive age: a systematic review and meta-analysis. J Nutr. 2014;144:906-914.

51. Mader TH, Tabin G. Going to high altitude with preexisting ocular conditions. High Alt Med Biol. 2003; 4:419-430.

52. Stapleton F, Edwards K, Keay L, et al. Risk factors for moderate and severe microbial keratitis in daily contact lens users. Ophthalmology. 2012;119:1516-1521.

53. White LJ, Mader TH. Refractive changes with increasing altitude after radial keratotomy. Am J Ophthalmol. 1993; 115:821-823.

54. Mader TH, White LJ. Refractive changes at extreme altitude after radial keratotomy. Am J Ophthalmol. 1995; 119:733-737.

55. Mader TH, Blanton CL, Gilbert BN, et al. Refractive changes during 72-hour exposure to high altitude after refractive surgery. Ophthalmology. 1996;103:1188-1195.

56. Nelson M, Brady S, Mader T, et al. Refractive changes caused by hypoxia after laser in situ keratomileusis surgery. Ophthalmology. 2001;198:542-544.

57. White L, Mader T. Refractive changes at high altitude after LASIK. Ophthalmology. 2000;107:2118.
58. Boes DA, Omura AK, Hennessy MJ. Effect of highaltitude exposure on myopic laser in situ keratomileusis. J Cataract Refract Surg. 2001;27:1937-1941.

59. Butler FK, Harris DJ Jr, Reynolds RD. Altitude retinopathy on Mount Everest, 1989. Ophthalmology. 1992;99: 739-746.

60. Alghadyan AA. Retinal vein occlusion in Saudi Arabia: possible role of dehydration. Ann Ophthalmol. 1993;25: 394-398.

61. Francis PJ, Stanford MR, Graham EM. Dehydration is a risk factor for central retinal vein occlusion in young patients. Acta Ophthalmol Scand. 2003;81:415-416.

62. Arjamaa O, Nikinmaa M. Oxygen-dependent diseases in the retina: role of hypoxia-inducible factors. Exp Eye Res. 2006;83:473-483.

63. Goldberg I, Moloney G, McCluskey P. Topical ophthalmic medications: what potential for systemic side effects and interactions with other medications? Med J Aust. 2008; 189:356-357.

64. Kaplan S, Talbot JF. Psychological benefits of a wilderness experience. In: Behavior and the Natural Environment. New York, New York: Springer; 1983:163-203.

65. Hill NR. Wilderness therapy as a treatment modality for atrisk youth: a primer for mental health counselors. J Ment Health Couns. 2007;29:338-349.

66. Fletcher TB, Hinkle JS. Adventure based counseling: an innovation in counseling. J Couns Dev. 2002;80:277-285.

67. Stott T, Hall N. Changes in aspects of students' selfreported personal, social and technical skills during a sixweek wilderness expedition in Arctic Greenland. $J$ Adv Educ Outdoor Learn. 2003;3:159-169.

68. Berman DS, Davis-Berman J. Wilderness therapy and adolescent mental health: administrative and clinical issues. Adm Policy Ment Health. 1991;18: 373-379. 